\title{
A Teoria da Obnubilação Brasílica na História da Música Brasileira: Renato Almeida e "A Sinfonia da Terra"
}

\author{
Maria Alice Volpe* \\ Universidade de Brasília
}

\section{Resumo:}

Trata da construção historiográfica do nacionalismo musical brasileiro enfocando obras fundacionais. Busca mapear concepçōes de identidade nacional no quadro das teorias "cientificistas" que influenciaram o pensamento sócio-antropológico brasileiro, a crítica literária e, conforme propomos aqui, a historiografia musical. A Escola do Recife explicou o "caráter nacional" segundo duas teorias: o determinismo racial e o determinismo geográfico (mesologismo). Tais concepçōes influenciaram os autores das primeiras histórias da música brasileira. O presente estudo aborda uma das vertentes da teoria do "caráter nacional" do período inaugural da musicologia brasileira. norteada pelo determinismo geográfico. O livro de Renato Almeida (1928) é analisado à luz da teoria da "obnubilação brasílica" de Araripe Júnior, que via no parâmetro 'meio' (clima e geografia) fator de conformação da cultura, fundamentado no mesologismo. Com base nas idéias de Araripe sobre a literatura, analisaremos o capítulo onde Almeida propõe que a formação do "caráter nacional" brasileiro deviase primordialmente ao impacto da natureza sobre o homem e a adaptação ao meio hostil dos trópicos, manifestando-se na música. A paisagem local foi critério historiográfico não apenas como "tópico" nacionalista, mas, sobretudo, na identificação de uma "expressividade" musical brasileira.

Palavras-chave: historiografia musical; nacionalismo; música e literatura

\footnotetext{
* Maria Alice Volpe, Doutora (Ph.D.) em Musicologia/ Etnomusicologia pela Universidade do Texas-Austin. EUA, é Professora de Musicologia da Universidade de Brasília, onde atua como Coordenadora do Programa de Pós-Graduação em Música. Dedicada à pesquisa da música brasileira do período colonial, séculos XIX e XX, bem como a questōes teóricoconceituais da musicologia, seus projetos têm recebido apoio do CNPq. CAPES e FAPESP. É Consultora Ad Hoc do CNPq e da CAPES (Brasil) e membro do Comitê Nacional (Brasil) do RILM-Répertoire International de Littérature Musicale.
} 
O presente artigo faz parte de um estudo mais amplo sobre a construçăo historiográfica do nacionalismo musical brasileiro, com enfoque nas obras fundacionais. ${ }^{1}$ Tal estudo busca mapear concepçōes de identidade nacional no quadro das teorias "cientificistas" que influenciaram o pensamento sócioantropológico brasileiro e os estudos literários; e, conforme propomos aqui, a historiografia musical. Desde as últimas décadas do séc. XIX e as primeiras décadas do séc. $X X$, as concepções de identidade nacional estavam fundamentadas nas teorias de formação do "caráter nacional" brasileiro, especialmente segundo as re-interpretaçōes que irradiaram da Escola do Recife, também chamada a "geração de 1870".

A Escola do Recife explicou o "caráter nacional" segundo teorias evolucionistas e deterministas que se polarizavam entre o determinismo racial e o determinismo geográfico (mesologismo). Tais concepções influenciaram os autores das primeiras histórias da música brasileira: Guilherme de Melo (1908), Renato Almeida (1926) e Mário de Andrade (1928). A partir deste último, estabeleceu-se como paradigma nacionalista a identificação de materiais folclóricos e populares na obra de compositores eruditos dos séculos XIX e XX. revelando uma visão culturalista tributária do parâmetro racial defendido por Silvio Romero.

Neste artigo abordaremos outra vertente da teoria do "caráter nacional" do período inaugural da musicologia brasileira, norteada pelo determinismo geográfico. As obras de Melo e de Almeida serão aqui analisadas à luz da teoria da "obnubilação brasílica" de Araripe Júnior, que via no parâmetro 'meio' (clima e geografia) fator de conformação da cultura, fundamentado no mesologismo. Com base nas idéias de Araripe sobre a literatura, analisaremos o capítulo onde

O presente artigo é baseado no Capítulo 1 "National identity in Brazilian music historiography", de minha tese de Doutorado (Ph.D.) Indianismo and Landscape in the Brazilian Age of Progress: Art Music from Carlos Gomes to Villa-Lobos, 1870s-1930s, defendida em 2001, na University of Texas-Austin, sob a orientação de Gerard Béhague. Constitui versão atualizada do trabalho apresentado no $13^{\circ}$ Encontro de Musicologia "Os Espaços da Música" da Associaçāo Portuguesa de Ciências Musicais-APCM, realizado na Universidade Nova de Lisboa, a 21 e 22 de outubro de 2005. 
Almeida propõe que a formação do "caráter nacional" brasileiro devia-se primordialmente ao impacto da natureza sobre o homem e a adaptação ao meio hostil dos trópicos, manifestando-se na música.

A musicologia brasileira nasceu e se institucionalizou na primeira metade do século XX, durante um período no qual a busca pela identidade nacional na música teve papel norteador na construção historiográfica, no que tange tanto à justificativa de tal empreitada quanto ao repertório que viria a compor tal cânone. O primeiro livro sobre o assunto. A música no Brasil, desde os tempos coloniais até o primeiro decênio da República (1908), de Guilherme de Melo.2 surgiu sob tal égide. Em sua nota introdutória, o autor dirige-se ao leitor brasileiro, afirmando sua intenção de "mostrar com provas exuberantes de que não somos um povo sem arte e sem literatura, como geralmente dizem", e reivindica que "pelo menos a música no Brasil tem feição característica e inteiramente nacional" (Melo, 1908, i). O horizonte nacionalista mostra-se ainda mais nítido no segundo livro sobre o assunto, a História da Música Brasileira (1926), de Renato Almeida, ${ }^{3}$ que entende a história da música brasileira como "a busca incessante de uma expressão própria" (Almeida, 1926, p. 108).

Essa necessidade de provar que a música brasileira possui identidade nacional inequívoca surgiu de um contexto anterior, onde se discutiam, na literatura e no pensamento sócio-antropológico brasileiro. os fundamentos supostamente científicos do "caráter nacional". Polarizavam-se aí dois parâmetros conformadores - raça e meio - segundo a influência das teorias cientificistas de Taine, $^{4}$ Spencer, ${ }^{5}$ Haeckel, ${ }^{6}$ e Buckle, ${ }^{7}$ entre outros, ${ }^{8}$ e suas reinterpretações

\footnotetext{
${ }^{2}$ Guilherme Teodoro Pereira de Melo (1867-1932), musicólogo brasileiro, foi nomeado bibliotecário do Instituto Nacional de Música em 1928 (Marcondes, 1998, p. 500). Conforme seu Prefácio, para escrever tal livro, ele pesquisou no Instituto Geográfico e Histórico da Bahia e no Gabinete Português de Leitura.

${ }^{3}$ Renato Almeida (1895-1981), musicólogo e folclorista, criou a Comissão Nacional de Folclore em 1947. promoveu as Semanas de Folclore em 1948, 1949. 1950 e 1952 e promoveu o primeiro Congresso Brasileiro de Folclore em 1951 (Marcondes, 1998, p. 18). ${ }^{4}$ Hippolyte Adolphe Taine (1828-1893), historiador e crítico literário francês, aplicou o determinismo à arte e à história literária, as quais supostamente corresponderiam à evolução intelectual e espiritual de cada sociedade. Principal teórico do naturalismo. 0 determinismo integral englobava os três fatores: raça, meio e momento (histórico).
} 
irradiadas pela Escola do Recife. Concedeu-se tamanho peso ao determinismo, supostamente exercido pela raça e pelo meio ambiente, que o próprio momento histórico brasileiro (que consistiria no "terceiro fator" de Taine) foi equacionado segundo os parâmetros raciais e mesológicos. Conforme Renato Ortiz,

Os parâmetros raça e meio fundamentaram o solo epistemológico dos intelectuais brasileiros de fins do século XIX e início do século XX. A interpretaçāo de toda a história brasileira escrita no período adquire sentido quando relacionada a esses dois conceitos-chaves. [...] Meio e raça constituíam em categorias de conhecimento que definiam o quadro interpretativo da realidade brasileira. (Ortiz, 1985, p. 16).

Silvio Romero é considerado pela crítica literária (Candido, 1945; Weber,

1997, p. 69-73) como tendo inaugurado (História da Literatura Brasileira, 1888) o método crítico, no Brasil, que buscou estabelecer uma explicação do texto literário pela realidade histórica que o determina. Ao considerar a literatura como expressão de uma dada realidade histórica, ensejou o estudo da especificidade do

${ }^{5}$ Herbert Spencer (1820-1903), filósofo inglês, afiliado ao evolucionismo, organicismo e sociologia biológica; e mais especificamente ao Evolucionismo aplicado à história e ao Darwinismo social.

${ }^{6}$ Ernest Heinrich Haeckel (1834-1919), biólogo e filósofo alemão, defendéu a fusão do conhecimento científico e filosófico e criou o monismo, uma teoria naturalista e psiquista que estendeu o evolucionismo de Darwin a todo o universo. Influenciado pelo evolucionismo de Darwin, não compartilhava com este o mesmo conceito de "selecão natural", como "a sobrevivência do mais apto", principal mecanismo pelo qual, segundo Darwin, se dava a evoluçāo das espécies. Haeckel sustentava que a sobrevivência das raças dependia de sua interação com o meio ambiente, um conceito atenuado de seleção natural. Haeckel sustentava que o meio ambiente agia diretamente nos organismos, produzindo novas raças - uma versão do Lamarckismo. Jean Baptiste Lamarck (17441829) formulou, em 1809, a primeira teoria da evolução, a qual se baseou em dois princípios fundamentais: a lei do uso e desuso e a lei dos caracteres adquiridos. Lamarck sustentava que o ambiente condiciona a evolução, e que a faculdade de adaptação ao meio leva ao aparecimento de características que permitem aos indivíduos adaptarem-se às condiçōes do ambiente onde vivem. Essa vertente Lamarckiana do pensamento de Haeckel influenciou o pensamento social brasileiro do final do séc. XIX e início do séc. XX.

${ }^{7}$ Henry Thomas Buckle (1821-1862), historiador inglês afiliado ao positivismo e determinismo, aplicou os métodos das ciências à história. Adotou a teoria climática. privilegiando o determinismo geográfico como fator preponderante na formação dos povos. "Buckle considerava a história um campo análogo às ciências naturais, que deveria examinar as leis pelas quais o meio físico age sobre o homem e a sociedade." (Ventura, 1991, p. 90-91).

${ }^{8}$ Para discussão mais aprofundada sobre a influência do cientificismo sobre intelectuais brasileiros, ver Candido (1945), Leite (1954), Sodré (1961), Skidmore (1974), Lima (1981), Ortiz (1985), Ventura (1991), Schwartz (1993) e Weber (1997). 
brasileiro ou, em suas palavras, "encontrar as leis que presidiram e continuam a determinar a formação do gênio, do espírito. do caráter do povo brasileiro" (Romero [1888] apud Weber, 1997, p. 69-70). Romero ressaltou que o brasileiro era um "novo tipo histórico", em cuja formação conferiu papel preponderante ao fator racial. Romero minimizou os prognósticos pessimistas das teorias cientificistas da época sobre os processos de miscigenação, por meio de uma teoria que afirmava que a mestiçagem do europeu com a raça negra era indispensável para que o homem pudesse sobreviver nos trópicos.

Contrapondo-se a Romero, Araripe Júnior formula uma teoria da "obnubilação brasílica", cuja ênfase no fator meio, compreendido segundo uma geografia determinista das zonas climáticas, explicava uma "queda psíquica" do colonizador, que teria implicaçōes essenciais para sua faculdade estética. A teoria da obnubilação brasílica deriva diretamente dos três fatores de Taine (raça, meio e momento histórico) e do mesologismo de Buckle, e indiretamente de Montesquieu e Buffon. ${ }^{9}$ Ao discutir a teoria da obnubilação brasílica em "Literatura brasileira" (in A Semana, 10-12-1887) e aplicá-la em "Estilo tropical: a fórmula do naturalismo brasileiro" (in Novidades, 22-3-1888), seguido de diversos artigos, Araripe Júnior expôs concepção crítica na qual "combinava a teoria climática a um modelo de orientação psicológica" e explicou a originalidade do estilo tropical como "resultado do impacto do meio local sobre as formas importadas da Europa" (Ventura, 1991, p. 17, 37, 89). Araripe privilegia sempre o meio à raça, ressaltando o impacto da natureza sobre o homem como o fenômeno explicativo das adaptações e transformações sofridas por portugueses e estrangeiros ante a paisagem nativa e os modos de vida tropical (Bosi, 1978, xiv-xvi, passim).

\footnotetext{
${ }^{9}$ Charles-Louis Montesquieu's De l'esprit des lois (1748) foi um precursor na formulação de uma teoria geral do clima aplicada às diferentes culturas de todo o planeta. George-Luis Leclerc Buffon, em Discours sur le style (1753) e Histoire naturelle de /'homme (1749-89) adotou a teoria climática de Montesquieu, classificando o homem, povos e civilizações por tipos climáticos, de acordo com uma taxonomia de zonas temperadas e tórridas. Formulou um conceito antropológico de 'estilo' como atributo da humanidade, inserido em uma teoria da civilização. Ver Ventura (1991, p. 19-43) para uma discussão detalhada sobre a influência de Montesquieu, Buffon, e Buckle na crítica literária brasileira.
} 
A disputa pela primazia do fator raça ou meio suscitou muitas polêmicas entre os intelectuais da época, tanto no campo da então chamada etnologia como no da literatura. Entretanto, essa disputa não teve o mesmo tom polêmico entre estudiosos da música. Enquanto Silvio Romero e Araripe Júnior travaram extensivas polêmicas quanto à predominância da raça ou do meio na formação do "caráter nacional", 10 estudiosos da música adotaram uma ou outra teoria sem maiores contendas.

Guilherme de Melo esposa uma visão etnológica, na qual os parâmetros étnicos e mesológicos amalgamam-se na formação do "brasileiro", ecoando em suas páginas introdutórias as palavras de Silvio Romero quanto aos princípios gerais do determinismo naturalista:

Foi pois na observância destes modos que procurei achar as leis étnicas que presidiram a formacão do gênio, do espírito e do caráter do povo brasileiro e sua música, bem como ainda de sua etnologia; isto é, como o povo português sob a influência do clima americano e em contato com o índio e o africano se transformou, constituindo o mestiço ou o brasileiro propriamente dito. (Melo, 1908, p. 6). ${ }^{11}$

A "influência do clima americano", observada por Melo, será desenvolvida mais amplamente por Almeida, duas décadas adiante, com base mais explícita na teoria da obnubilação brasílica de Araripe Júnior, conforme propomos neste estudo. A relação estabelecida entre a história da música brasileira de Renato Almeida e o pensamento de Araripe Júnior torna-se evidente pela semelhança entre ambos os textos e é corroborada pela dedicatória a um amigo comum, Graça Aranha, ${ }^{12}$ escritor e intelectual reconhecido por ter levado

\footnotetext{
${ }^{10}$ Ver Ventura (1991, p. 79-84) sobre as polêmicas entre Silvio Romero e Araripe Júnior no campo da crítica literária, veiculadas em seus livros e artigos publicados na imprensa diária da época.

${ }^{11}$ As palavras sublinhadas de Almeida coincidem com a citação de Romero (apud Weber. 1997, p. 69-70) mencionada acima.

12 José Pereira da Craça Aranha (1868-1931), escritor, magistrado e diplomata brasileiro. discípulo da figura líder da Escola do Recife. Tobias Barreto. Consagrado com o romance Canaã (1902), ingressou ainda jovem na Academia Brasileira de Letras, com a qual romperia escandalosamente em 1924. Durante a Semana de Arte Moderna (1922). proferiu a conferência $A$ emoção estética na arte moderna, sendo o único intelectual de
} 
o pensamento moderno da Escola do Recife para os modernistas do século XX (Martins, 1977, v. 6, p. 55). Renato Almeida é, portanto, o primeiro estudioso da música brasileira a se ressentir da influência da Escola do Recife em sua obra, estabelecendo as premissas de sua posiçāo crítica e estética. Numa fase inicial de seu pensamento musicológico, cristalizado na primeira edição de História da Música Brasileira (1926), que abordamos neste estudo, Renato Almeida enfatizou a importância do meio na formação da cultura, compartilhando a teoria da obnubilação brasilica de Araripe Júnior; conforme sugere a dedicatória, por influência de Graça Aranha. Numa segunda fase, representada pela segunda ediçāo (1942) e por obras posteriores, e em consonância com Mário de Andrade, volta-se para o parâmetro "raça", buscando um aprofundamento maior das questōes étnicas do folclore e da miscigenação. ${ }^{13}$

No capítulo introdutório "A sinfonia da terra" (Almeida, 1926, p. 11-17), rejeitado em épocas posteriores devido ao seu estilo de redação presumidamente rebuscado, é exatamente onde Almeida expõe sua posição crítica e estética. Tal texto introdutório reflete a influência da crítica literária na historiografia musical. Sob a influência de Araripe Júnior, em "A sinfonia da terra". Almeida formula extensivamente sua própria versão da teoria da obnubilaçāo brasílica aplicada à música brasileira, dramatizada pela luta de geraçōes de portugueses, e depois brasileiros, contra a natureza tropical. Almeida reconhece o impacto da natureza tropical sobre a psicologia e a alma brasileira. Como outros autores da época, Almeida "tece várias considerações a respeito da vinculação entre as características psíquicas do homem e sua dependência do meio ambiente". ${ }^{14}$ Transcreveremos a seguir, intermitentemente, trechos de "A sinfonia da terra", de Almeida. Embora não disponhamos de espaço para apresentar a introdução de Almeida em sua totalidade, buscaremos manter a sua linha de argumentação.

renome a apoiar os vanguardistas. Publicou ainda Malarzarte (1911) e A Estética da Vida (1921).

${ }_{14}^{13}$ Esse aspecto é exposto em outro trabalho da autora. Ver Volpe (2001).

${ }^{14}$ Estabelece-se aqui um paralelo com o comentáriò de Ortiz (1985, p. 16) sobre Nina Rodrigues. 
Almeida inicia descrevendo o meio tropical e suas maravilhas, tornando mais compreensível sua explanação posterior a respeito do impacto da natureza sobre o homem. O uso abundante da linguagem poética não constitui mero exercício de erudição, mas é indicativo da visão do autor sobre as impressões sensoriais avassaladoras da natureza sobre a racionalidade do homem e também uma descrição metafórica (ou metalinguística) da musicalidade da natureza tropical.

O mundo em torno é todo ele uma alegoria. Ao meio da luz, rebrilham e fulguram as coisas, tocadas de oiro, como num incêndio maravilhoso. A cor cria e transfigura, nos reflexos cambiantes e sutis, entre os tons intensos e os motivos suaves; numa surpreendente harmonia. O sol esbraseia, queima as florestas, escalda a terra e põe no mar requintes de brilhos, dando à natureza a alegria e o torpor, o deslumbramento e a melancolia. Na mata, torram as folhagens, arrebentam os troncos, donde escorrem as resinas mornas, e a terra mesma se abre, numa ânsia cruel e voluptuosa. A soalheira é uma alucinação. Não só dá cor, mas também som. Vede a sinfonia prodigiosa que se levanta! Gritos vermelhos, melopéias verdes, alaridos de folhas secas, soluços lilases e imprecaçōes cinzentas. São as vozes da selva que estrugem. Sons de violinos e oboés, flautas, violoncelos, tambores, fagotes e timbales, harmonizando um ritmo bárbaro e grandioso. Até o silêncio é uma voz grave e perturbadora, que ressoa e amedronta. Tudo canta; as ramarias gementes, os rios murmurosos, as cascatas em corais, as cigarras estridentes, os besouros e os moscardos zumbindo e a passarada, na politonia dos gorjeios e gritos, dos canários, das arapongas e dos coleiros. As flores silvestres e os frutos bravos são notas vibrantes e em tudo há som, nesse rumor indeciso da terra virgem, que é toda inteira um canto de alegria e de êxtase. (Almeida, 1926, p. 11-13).15

Almeida narra a aventura do português nos trópicos em sua dimensão psicológica. O texto de Almeida guarda similaridades óbvias com a explanação de Araripe Júnior sobre o processo da "obnubilação brasílica". A esta, Almeida acrescenta a contraparte musical na luta entre o homem e a natureza, entre razão e ordem natural.

O homem, que veio singrando os mares nas caravelas, com a nostalgia da pátria distante, pasmou-se no meio ardente do mundo estranho. Ao deslumbramento sucedeu a fadiga e a lassidão e, ao ritmo brutal da

${ }^{15}$ Grifo nesta e demais citações são da autora deste artigo para efeito de ênfase. 
natureza, eloquente na sua festa de luz e de som, ficou humilhado, porque a tessitura da sua voz era mesquinha para se altear na orquestraçāo fortíssima. Desolado e triste, melancólico num palácio de ouro e pedrarias, chorou, e seu canto foi uma melopéia dolente. de saudade, que lhe irrompia do coração amedrontado no fulgor da terra nova. $\mathrm{Na}$ sua fraca imaginativa de europeu não se afinavam os timbres da sinfonia brasileira. que amesquinhava o estrangeiro ousado. Era a primeira defesa da terra contra o conquistador audaz. Humilhava-o. Cantaria uma canção dolorosa e melancólica, por entre o alvoroço perene de suas harmonias formidáveis. (Almeida, 1926, p. 13-14).

O confronto entre a música da natureza e a música do homem é mais do que uma metáfora da luta entre natureza e civilização. Além de sustentar que o som da natureza tem impacto sobre o homem, o autor propōe que a situação histórica da colonização condiciona uma característica psicológica do novo português e seus descendentes brasileiros, que será expressa pela sentimentalidade de sua música.

Dominaria assim a terra bravia, com sua música de metais estridentes e melodias largas. Da mesma forma que não temeria o embate da natureza para vencê-la, varando de lado a lado, em bandeiras destemidas, a selva misteriosa e terrível, não se calaria ante o seu concerto de mil vozes. Cantaria, triste embora, até que seus filhos, já nascidos no cenário prodigioso, pudessem sentir no calor do sangue essa linguagem harmoniosa das coisas, interpretando-a e unindo a sua voz à delas no mesmo tom de exaltaçāo. Os que nasceram no país novo, já traziam a marca do deslumbramento. Eram imaginosos. FremiamIhes na alma as ânsias da terra rude, mas no íntimo do coração ficara o travo de melancolia. O êxtase, por vezes cessa, para dar lugar à tristeza e ao abatimento, que se traduzem nas cordas líricas de um sentimentalismo um pouco amargo. Aquela dor de seus pais, perdura neles, como um tributo implacável da origem diferente ao mundo americano. Mais uma vez a terra se vinga de seu desvirginador. Enquanto ressoarem nos seus ouvidos as vozes da natureza, aperta-lhes o coração a nostalgia de amesquinhados. Esse é o fundo de tristeza da psique brasileira. (Almeida, 1926, p. 14-15).

A musicalidade brasileira é afirmada e explicada minuciosamente nos termos do determinismo mesológico: "só poderíamos ser musicais", diz Renato Almeida. A natureza tropical não apenas condiciona a musicalidade brasileira como também garante sua originalidade. O texto conclui com um manifesto 
nacionalista que enfatiza a importância do meio. mais do que da cultura étnica. na formação da musicalidade brasileira.

Não podíamos deixar de ser musicais. Só as naturezas frias são mudas e a nossa sinfoniza a própria luz. Pouco importam as formas do canto popular, as modificações autóctones ou importadas; ficou o ritmo brasileiro. com uma cor dourada, cheia de sol, fulgente. maravilhosa. Com ele havemos de criar a nossa música e os que o desprezarem não construirão nada de definitivo, porque fora do meio as obras são precárias. Nessa massa rude é que havemos de plasmar a estátua ideal, que renascerá ao sopro do gênio, com carne e sangue, viva e translúcida. Ouçamos as vozes da terra e criaremos o ritmo de nossa arte, profunda e imortal. As enxertias só produzem monstros. Saibamos fazer de todos os toques do concerto natural um motivo de arte e criaremos o nosso mundo sonoro. (Almeida, 1926, p. 15-16).

O reconhecimento da teoria da obnubilação brasílica como conceito norteador do pensamento de Almeida é fundamental para a compreensão de sua assertiva "fora do meio as obras são precárias", pois para Almeida "meio" é natureza, fator geográfico-climático, mais do que fator sócio-antropológico. Para a interpretação da palavra "meio", considere-se a influência de Araripe Júnior, o qual reinterpretou os três fatores de Taine (raça, meio e momento histórico) sob a ótica do mesologismo de Buckle.

O estilo poético do texto de Almeida tem provocado uma reação negativa nos estudiosos mais recentes, preocupados com abordagens mais "acadêmicas" ou "científicas" no estudo da música brasileira. Entretanto. é importante observar que paradoxalmente as metáforas usadas por Almeida derivam de visões cientificistas de sua época, especialmente na re-interpretação de Araripe Júnior e sua teoria do impacto da natureza sobre os indivíduos e, conseqüentemente, sobre a formação da cultura. É a partir dessa perspectiva que deve ser interpretado o discurso de Almeida, construído sobre metáforas, ao comentar as obras de compositores brasileiros. Enquanto algumas passagens parecem refletir uma visão estética romântica de Almeida, a respeito da "inspiração" no processo criativo, outras se situam inequivocamente em sua postura mais "cientificista", respaldada pela teoria da obnubilação brasílica. No primeiro caso estaria sua crítica à obra de Carlos Gomes, que destaca o impacto da paisagem brasileira na 
alma e na música do compositor, mencionando "o espetáculo sugestivo da nossa paisagem", com sua "sinfonia de acordes majestosos" e cuja "impressão admirável e pujante da terra the perduraria no espírito". Conclui então que em "sua obra fulgiriam as linhas claras desse primeiro contato com a natureza." (Almeida, 1926, p. 84).

Essa visão romântica do gênio criador pode ser identificada ainda em seus comentários sobre a importância da natureza tropical na música de VillaLobos, qualificando-o como "transfigurador" e cuja imaginaçāo "se desenvolve através das impressões do meio... como uma sugestão profunda da natureza maravilhosa." (Almeida, 1926, p. 174).

Suas observações sobre o "profundo sentido da natureza" (Almeida, p. 119), revelado na música de Alberto Nepomuceno, vão desde expressōes metafóricas, como a essencialização do prelúdio do Garatuja. "feito com um cheiro quente da terra" (Almeida, p. 117), até afirmações mais próximas da teoria da obnubilação brasílica que explicam "a suave nostalgia brasileira" pelo "calor e a vibração, o sentido da natureza exorbitante, que melancoliza o homem" (Almeida, p. 116-117).

Enquanto na música de Nepomuceno a natureza é pintada e expressa musicalmente pelo seu impacto psicológico, na música de Braga, a natureza é também humanizada ao receber atributos emocionais da própria cultura sobre a qual exerceu influência. Destacando que Francisco Braga "é um paisagista de mérito". Almeida acrescenta que no poema sinfônico Marabá, ao "canto triste" da índia mestiça, "todas as vozes se unem [...] como se a natureza ardente precisasse se humanizar naquela mágoa indefinível." O prelúdio da ópera Jupyra, definido por Almeida como "uma página muito brasileira", consubstancia mais uma vez a teoria da obnubilação brasílica, pois "é um poema da nossa natureza, no reflexo dessa melancolia a que somos levados pelo próprio mundo que nos cerca, na sua transbordante opulência" (Almeida, p. 129-130).

Almeida torna inequívoca sua adesão ao postulado da obnubilação brasílica ao reiterar que "o meio estranho, já o mostramos, nos faz tristes e, na melancolia resultante, vamos decifrando a vida. É o motivo máximo da arte 
brasileira" (Almeida, p. 118). Assim como Araripe Júnior, Almeida defende que a identidade nacional residiria numa característica psicológica, sendo esta resultante do impacto da natureza sobre o homem. A "incerta psique brasileira" oscila entre o "êxtase" e o "deslumbramento" diante do "fulgor da natureza" e a "melancolia" e a "nostalgia". E para não deixar dúvida. Almeida assegura:

Se precisássemos de uma viva e fulgurante demonstração pelo que vimos insistindo neste ensaio, sobre a influência do meio na obra de arte, a música do Sr. Villa-Lobos nos daria a mais absoluta. Sem ser um simples paisagista. que copiasse a natureza, nem um folclorista, que viesse aproveitando os motivos populares para estilizaçōes, sendo antes uma personalidade exorbitante, o Sr. Villa-Lobos tem a animar a sua arte o espírito da terra, no fulgor da natureza, na melancolia do homem, enfim na incerta psique brasileira [...] os característicos da alma brasileira. (Almeida, 1926. p. 169170).

Diversas passagens do texto de Almeida (1926) assemelham-se a excertos de Araripe Júnior. Vejam-se, por exemplo, trechos da "Carta sobre a literatura brasílica" (1869), onde Araripe prenuncia sua teoria sem, no entanto, denominála como tal. Aí, Araripe Júnior discorre sobre a "natureza cheia de esplendores da América", "a imensa floresta onde só habita esse silêncio cheio de vozes harmoniosas", a originalidade da literatura americana, "filha do assombro e da admiração", "os raios do ardente e vivificante sol dos trópicos"; em seu discurso, Araripe interroga sobre "os resultados desta transmutação" e conclui que "incontestavelmente a natureza tem uma influência poderosíssima sobre as imaginaçōes" (apud Bosi, 1978. p. 9-26, passim). Observem-se ainda visões explicativas da originalidade brasileira absorvidas de ensaios como "Literatura Brasileira" (1887), "Estilo tropical" (1888) e "Gregório de Matos" (1893), nos quais Araripe Júnior propõe a teoria da obnubilação e fala sobre a "ação catalítica exercida pela nova terra na quimificação da psicose do colono" (apud Cairo. 1996. p. 57). Tanto em Araripe Júnior quanto em Renato Almeida há intensa sobreposição de explicaçōes de teor "cientificista" e estilístico, cujas terminologias soam bastante peculiares para décadas posteriores, quando da superação de tais referenciais teóricos e explanatórios. 
O estilo poético de Almeida, quando enfocado sob a perspectiva da teoria da obnubilação brasílica de Araripe Júnior, adquire novo sentido, não mais restrito ao linguajar poético de um "homem das letras", mas reflete um intelectual sintonizado com as teorias cientificistas da época, buscando equacionar a identidade nacional na música. A teoria do "caráter nacional" esposada por Almeida define a "alma brasileira" como "incerta psique brasileira", respaldada pelo determinismo geográfico-climático (mesologismo).

Buscamos demonstrar neste artigo que a natureza local foi critério historiográfico não apenas como "tópico" nacionalista, mas, sobretudo, na identificação de uma expressividade musical "brasileira". Acima de tudo, o reconhecimento da teoria da obnubilação brasílica como conceito norteador da primeira fase do pensamento de Almeida é fundamental não apenas para a releitura de sua linguagem altamente poética, como também para uma compreensāo do solo epistemológico dos textos fundacionais da historiografia musical brasileira.

\section{Referências}

ALMEIDA, Renato. História da música brasileira. [1926]. 2. ed. corrigida e aumentada. Rio de Janeiro: F. Briguiet, 1942.

ARANHA, Graça. A Estética da Vida. Rio de Janeiro: Garnier, 1921.

ARARIPE JÚNIOR, Tristão de Alencar. Obra crítica de Araripe Júnior. In: COUTINHO, Afrânio (Org.). Rio de Janeiro: Ministério da Educaçāo e Cultura; Casa de Rui Barbosa, 1958-70. 5 vols.

BOSI. Alfredo. Araripe Júnior: teoria crítica e história literária. Rio de Janeiro: Livros Técnicos e Científicos: São Paulo: Editora da Universidade de São Paulo, 1978.

CANDIDO. Antonio. O método crítico de Silvio Romero. [1945]. São Paulo. Editora da Universidade de São Paulo, 1988.

CAIRO. Luiz Roberto. O salto por cima da própria sombra: O discurso crítico de Araripe Júnior: uma leitura. São Paulo: Annablume, 1996.

COUTINHO, Afrânio. Araripe Júnior e o nacionalismo literário. In: Conceito de Literatura Brasileira. [1959]. Petrópolis: Vozes, 1981.

DUPRAT, Regis. Evolução da historiografia musical brasileira. Opus 1, p. 32-36, 1989.

LEITE, Dante Moreira. O caráter nacional brasileiro: história de uma ideologia. [1954]. 5. ed. São Paulo: Ática, 1992. 
LIMA, Luis Costa. A crítica literária na cultura brasileira do século XIX. In: Dispersa Demanda: ensaios sobre literatura e teoria. Rio de Janeiro: Editora Francisco Alves, 1981.

MARCONDES, Marcos (Ed.). Enciclopédia da Música Brasileira. 2. ed. São Paulo: Art Editora; Itaú Cultural, 1998.

MARIZ, Vasco. Três musicólogos brasileiros: Mário de Andrade, Renato Almeida, Luís Heitor Correa de Azevedo. Rio de Janeiro: Civilização Brasileira; Brasília: Instituto Nacional do Livro, 1983.

MARTINS, Wilson. História da Inteligência Brasileira, São Paulo: Cultrix, 1977-1978. v. 5. 6.

MELO, Guitherme Teodoro Pereira. A música no Brasil, desde os tempos coloniais até o primeiro decênio da República. [1908]. 2. ed. Rio de Janeiro: Imprensa Nacional. 1947.

ORTIZ, Renato. Memória coletiva e sincretismo científico: as teorias raciais do século XIX. In: Cultura Brasileira e Identidade Nacional. [1985]. 5. ed. São Paulo: Brasiliense, 1994.

PAES, José Paulo. Canaã e o ideário modernista. São Paulo: Editora da Universidade de São Paulo, 1992.

SCHWARCZ, Lilia Moritz. O espetáculo das raças: cientistas, instituiçōes e questão racial no Brasil, 1879-1930. São Paulo: Companhia das Letras, 1993.

SKIDMORE, T. E. Black into White; race and nationality in Brazilian thought. New York: Oxford University Press, 1974.

SODRÉ. Nelson Wernek. A ideologia do colonialismo: seus reflexos no pensamento brasileiro. Rio de Janeiro: Ministério da Educação e Cultura, Instituto Superior de Estudos Brasileiros, 1961.

VENTURA, Roberto. Estilo tropical: a natureza como pátria. Ideologies \& literature. Minneapolis, 2. no. 2, p. 145-158, 1987. Republicado em: Remate de males. Campinas, 7, p. 27-38, 1987.

VENTURA, Roberto. Estilo tropical, história cultural e polêmicas literárias no Brasil. 18701914. São Paulo: Companhia das Letras, 1991.

VOLPE, Maria Alice. National identity in Brazilian music historiography. In: Indianismo and Landscape in the Brazilian Age of Progress: Art Music from Carlos Gomes to VillaLobos, 1870s-1930s. 2001. cap. 1. Tese de Doutorado - Ann Arbor, Michigan: UMI-Research Press, 2002.

WEBER, João Hernesto. A nação e o paraiso: a construção da nacionalidade na historiografia literária brasileira. Florianópolis: Editora da Universidade Federal de Santa Catarina, 1997.

Maria Alice Volpe: mavolpe@gmail.com

Recebido e aprovado em 04 de junho de 2007 